\title{
FRICTION AND WEAR BEHAVIOR IN PLASMA SPRAYED COATINGS
}

\begin{abstract}
B. ANToszewsKI
Technical University of Kielce, Al. 1000-lecia P.P. 7, 25-314 Kielce, Poland

The wear behavior and the mechanism of plasma sprayed WC12Co, $\mathrm{Cr}_{2} \mathrm{O}_{3}$ and $\mathrm{Al}_{2} \mathrm{O}_{3}$ coatings in sliding contact with steel bronze and carbon graphite were studied with block-on-ring arrangement. The coefficient of friction and wear rate of these coatings were measured at dry friction conditions. The worn surfaces of the coatings were examined employing the scanning electron microscope. The results obtained that the wear mechanism of coatings changes for different kinds of layers.
\end{abstract}

PACS numbers: $81.40 . P q, 52.75 .-\mathrm{d}$

\section{Introduction}

High hardness, high chemical resistance, stability of chemical constitution, also in higher working temperatures as well as peculiar porosity and presence of some oxidated elements of sprayed material are the most characteristic features of plasma sprayed coatings. These are some features to be taken advantage of in designing of some kinds of tribological junctions, especially those working in dry friction conditions [1, 2]. Most important are the matchings of $\mathrm{Al}_{2} \mathrm{O}_{3}, \mathrm{Cr}_{2} \mathrm{O}_{3}$ and WC12Co coatings with carbon graphite (E28), bronze (BA1032) and steel $(1 \mathrm{H} 18 \mathrm{~N} 9 \mathrm{~T})$. Better identification of their wear processes, as well as the friction parameters of such matchings may be of use and even serve as a basis to achieve better wear characteristics of dry friction, heavy duty, pairs.

\section{Research procedure}

The $\mathrm{Al}_{2} \mathrm{O}_{3}, \mathrm{Cr}_{2} \mathrm{O}_{3}$ and WC12Co coatings with a PN 120 torch argon PLANCER plasmotron were sprayed on ring shaped test pieces. The $\mathrm{Al}_{2} \mathrm{O}_{3}$ and $\mathrm{Cr}_{2} \mathrm{O}_{3}$ powders were of local production, while the WC12Co was an AMDRY no. 1301 produce. The applied spraying parameters were: spraying distance $150 \mathrm{~mm}$, current intensity $600 \mathrm{~A}$, voltage $60 \mathrm{~V}$. The thickness of applied coatings was $0.3 \mathrm{~mm}$. The polished size of each test piece diameter was $35 \mathrm{~mm}$ with great dimensional accuracy. According to the requirements of the documentation of the tester in use the measuring blocks were prepared in form of friction blocks $15.75 \times 10 \times 6.35$ $\mathrm{mm}$. The materials of the test blocks were: BA1032 bronze, E28 resin impregnated 


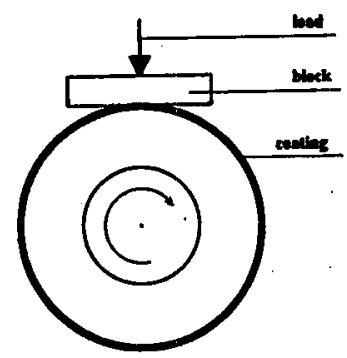

Fig. 1. The tested friction pair.

carbon graphite and 1H18N9T steel. All tribological researches were conducted with the use of T-05 roll block type tester in accordance with the US standard ASTMD 2714, ASTMD 2981. The tested friction pair diagram is shown in Fig. 1. Method I [3] measurements were applied to evaluate the wear of samples in dry friction conditions and method II [3] was used to establish the frictional drag. Applied measuring ranges for roll block pressures were: $P=300$ to $2400 \mathrm{~N}$ and $n=44$ to $175 \mathrm{rpm}$ in method $\mathrm{I}$ and accordingly $P=600 \mathrm{~N}$ and $n=180 \mathrm{rpm}$ in method II testings. The friction force and the mass temperature of the test blocks were measured and registered directly by the tester. Periodically, according to the research project, measurements of the block wear (with the circumferential abrasion method) and the ring wear (with the mass method) were taken. Treble repetition of each of those sets of measurements enabled application of EXCEL sheet calculating 5.0 data handling. The wear image analysis was performed with the use of a JOEL JSM- 5400 scanning microscope.

\section{Research results}

A typical diagram of the progress of the measurements obtained in method II testings for the $\mathrm{Cr}_{2} \mathrm{O}_{3} / \mathrm{E} 28$ matching is shown in Fig. 2. Figure 3 graphs and Fig. 4 diagrams provide an image of the frictional parameters measured for respective dry friction pairs. As was noticed, the interdependence between friction factor, contact pressure factor and the factor of relative speed of the interacting elements of the plasma coated pair is of the same character as is in case of friction between other materials (Fig. 3). The observed friction coefficient value changes ranged as is shown in Table I.

The evaluated ranges of the antiscuffing resistances are shown in Fig. 4. The matchings based on WC12Co coated test rings are the quickest to seize. The highest PV index values are reached with all the coatings matched with BA1032 bronze. The friction coefficient value diversification for the WC12Co coated ring pieces matched with any block material indicates that the abrasion wear process is in that case of a completely different character than by all other matchings. The abrasive process analysis was based on the results of measurements obtained with the method II testing application. The diagram in Fig. 5 shows the wear versus time function for the $\mathrm{Cr}_{2} \mathrm{O}_{3} / \mathrm{E} 28$ slip pair. In Table II the values of calculated wear intensities of all the frictional matchings of the tested materials are 


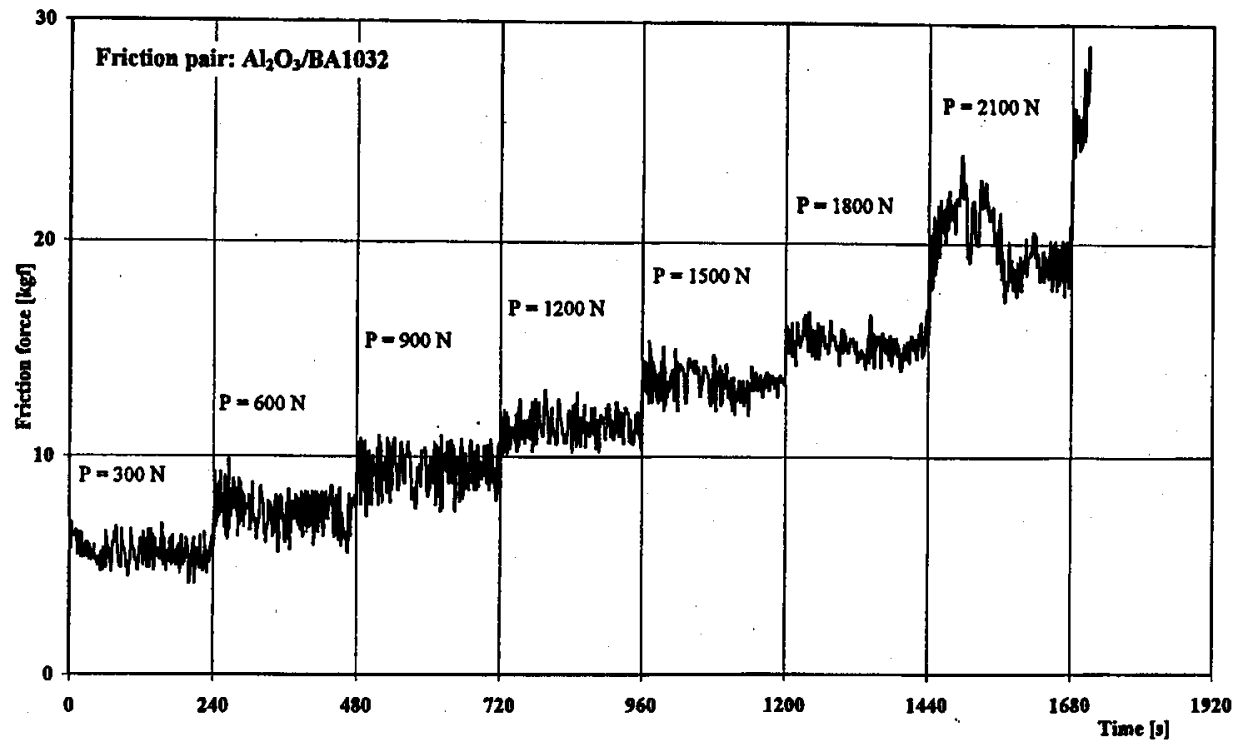

Fig. 2. A typical method II test registration course $\left(\mathrm{Al}_{2} \mathrm{O}_{3} / \mathrm{BA1032}\right)$. Every following stages on the diagram present friction force with load increasing $P=300-2100 \mathrm{~N}$. For every particular load 4 rotational velocities have been applied $n=44,88,132,176 \mathrm{rpm}$ which have been changed every $60 \mathrm{~s}$. Parameters of investigation run in method I were constant; $P=600 \mathrm{~N}, n=180 \mathrm{rpm}$, time of single run was 300 minutes.

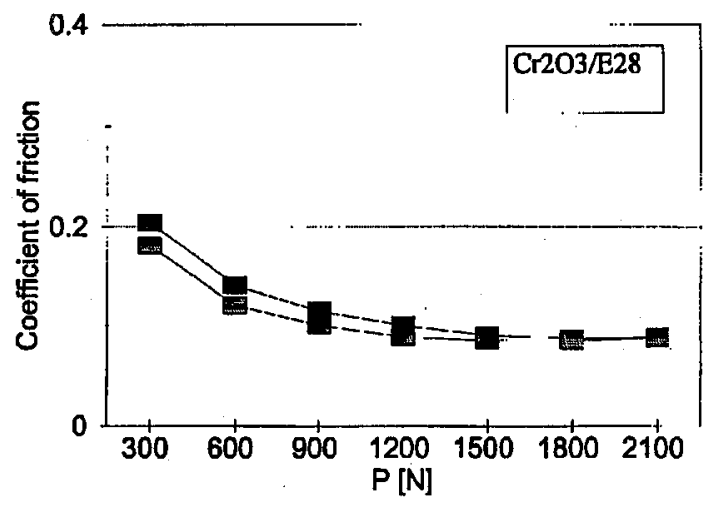

$v=44 \mathrm{rmm} v=175 \mathrm{rpm}$

Fig. 3. The friction coefficients versus load and speed interdepedence.

given. Notwithstanding all the realized with method II successful researches, it proved to be impossible to obtain a set of full length tests with any matching containing WC12Co coated ring piece. It regards $1 \mathrm{H} 18 \mathrm{~N} 9 \mathrm{~T} / \mathrm{WC12Co}$ and

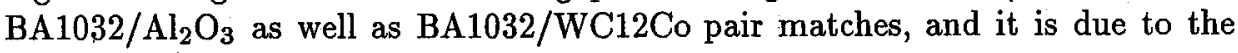




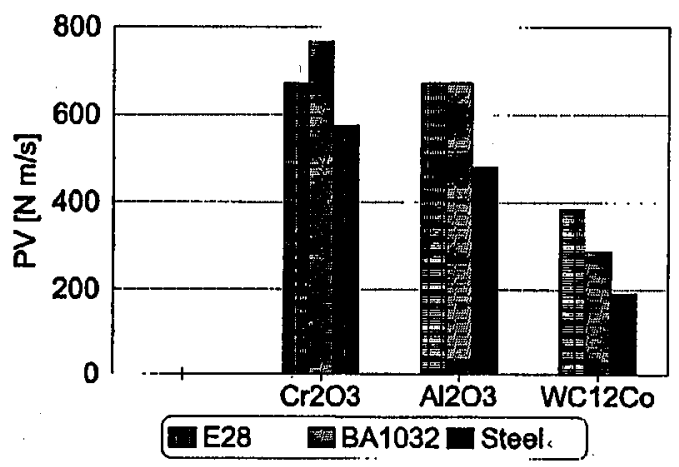

Fig. 4. The coat material's anitiseizure resistance.

TABLE I

Values of friction coefficient.

\begin{tabular}{c|c|c|c|c|c|c}
\hline \hline$\mu$ & \multicolumn{2}{|c|}{ E28 } & \multicolumn{2}{c|}{ BA1032 } & \multicolumn{2}{c}{ 1H18N9T } \\
\cline { 2 - 7 } & Meth. I & Meth. II* & Meth. I & Meth. II* & Meth. I & Meth. II* \\
\hline $\mathrm{Cr}_{2} \mathrm{O}_{3}$ & 0.18 & $0.08 \div 0.19$ & 0.09 & $0.08 \div 0.18$ & 0.22 & $0.08 \div 0.22$ \\
$\mathrm{Al}_{2} \mathrm{O}_{3}$ & 0.18 & $0.08 \div 0.18$ & 0.09 & $0.08 \div 0.19$ & 0.22 & $0.08 \div 0.19$ \\
$\mathrm{WC12Co}$ & 0.17 & $0.08 \div 0.19$ & 0.23 & $0.10 \div 0.30$ & 0.14 & $0.10 \div 0.18$ \\
\hline
\end{tabular}

*. Lower values of friction coefficient in method II are connected with parameters, $P=300 \mathrm{~N}$ and $n=44 \mathrm{rpm}$, upper values are connected with $P$ and $n$ before seizing.

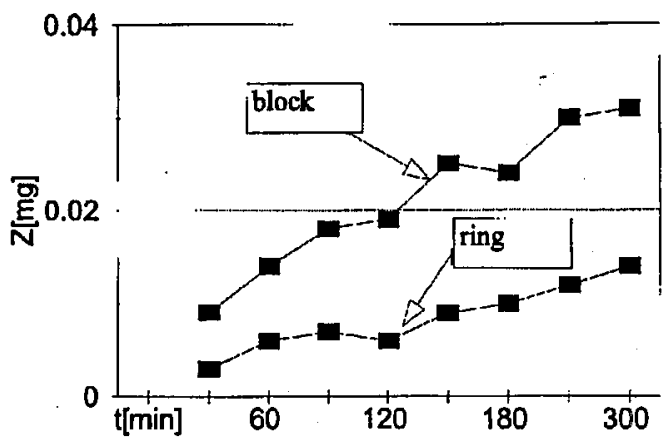

Fig. 5. The wear versus time function for $\mathrm{Cr}_{2} \mathrm{O}_{3} / \mathrm{E} 28$ pair.

seizing effect. The formation of a stable superficial sublayer on the contact surfaces of such a pair proved to be too fragile and undurable and its breakdown was almost immediately followed by intense attrition, which resulted in seizure. Positive results for the tested materials achieved during the method II testings proved that these matchings are, in spite of the seizures during the research course, able 
TABLE II

Values of wear rate.

\begin{tabular}{c|c|c|c|c|c|c}
\hline \hline$[\mathrm{mg} / \mathrm{h}]$ & \multicolumn{2}{|c|}{ E28 } & \multicolumn{2}{c|}{ BA1032 } & \multicolumn{2}{c}{ 1H18N9T } \\
\cline { 2 - 7 } & Block & Ring & Block & Ring & Block & Ring \\
\hline $\mathrm{Cr}_{2} \mathrm{O}_{3}$ & 0.010 & $2.0 \times 10^{-3}$ & 0.025 & $0.72 \times 10^{-3}$ & $(0.029)^{*}$ & $\left(4.4 \times 10^{-3}\right)$ \\
$\mathrm{Al}_{2} \mathrm{O}_{3}$ & 0.011 & $2.6 \times 10^{-3}$ & 0.032 & $1.80 \times 10^{-3}$ & $(0.039)^{*}$ & $\left(3.1 \times 10^{-3}\right)$ \\
$\mathrm{WC12Co}$ & 0.018 & $4.2 \times 10^{-3}$ & - & - & - & - \\
\hline
\end{tabular}

${ }^{*}$ The results obtained in tests ending with a seizure.
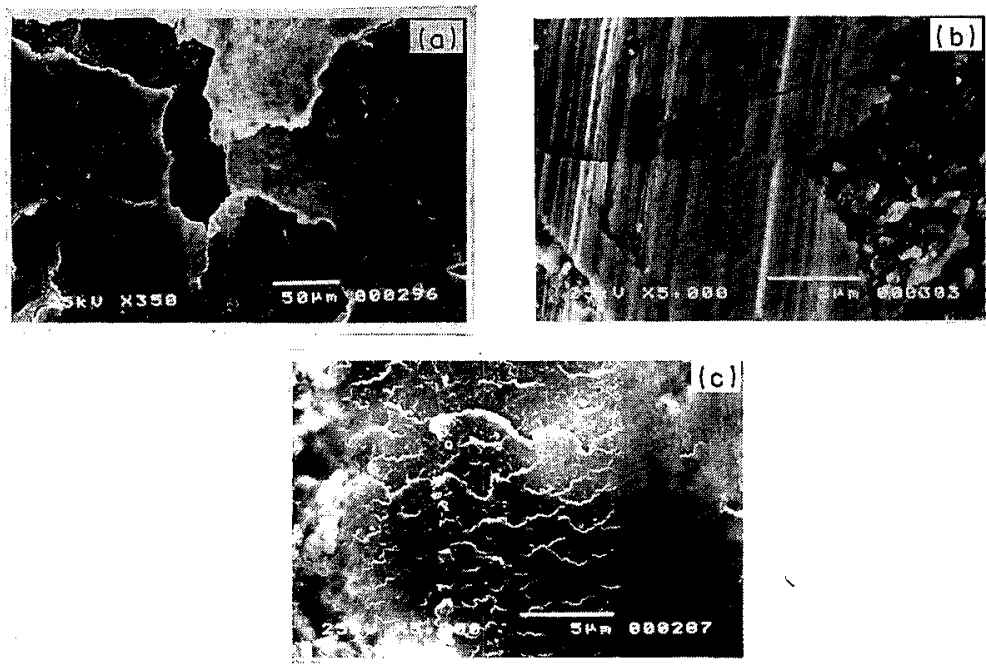

Fig. 6. Worn surfaces after seizing of: $\mathrm{Cr}_{2} \mathrm{O}_{3}\left(\mathrm{Cr}_{2} \mathrm{O}_{3} / \mathrm{BA1032}\right)$ SEM $350 \mathrm{X}$ (a), WC12Co (WC12Co/E28) SEM $5000 \mathrm{X}$ (b), $\mathrm{Cr}_{2} \mathrm{O}_{3}\left(\mathrm{Cr}_{2} \mathrm{O}_{3} / \mathrm{E} 28\right)$ SEM $5000 \mathrm{X}$ (c).

to carry higher than loads used in the described tests if the load varying could be applied in a more gradual way. Our wear image analysis reveals the size of diversification and the complexity of the wear process concerning various match slide pairs. An illustration of this effect is given by Fig. 6a, showing a seizure between $\mathrm{Cr}_{2} \mathrm{O}_{3}$ coated ring and a BA1032 block. A breakdown of the BA1032 bronze adhesive sublayer, due to its fatigue cracking discernible in form of exfoliation of oxidated during the test bronze flakes is here evident. It was noticed that in case of carbide coatings the adhesive sublayer created during the tests interrupted before breakdown seizure, are by far thinner than those formed in tests with the ceramic coatings. It indicates that the adhesion between the carbide coatings and the block material is weaker. The way of wear off of the carbide coatings is different than the attrition of all other coatings (Fig. 6b). In case of the carbide coatings the wear process is mainly due to formation of a set of fatigue microcracks on the matrix coating boundary interface and subsequent crumbling away of the so disengaged 
coat material particles. The formation of cracks in carbon graphite layer and the mechanism of subsequent expansion of cracks in $\mathrm{Cr}_{2} \mathrm{O}_{3}$ plasma coatings is shown in Fig. 6c. The cracks initiation developes on the carbon graphite adhesive layer and after the initiation spreads into the coating.

\section{Conclusion}

1. The generation of abrasive wear of WC12Co and $\mathrm{Cr}_{2} \mathrm{O}_{3}$ coatings is due to penetration of thermo and fatigue microcracks which are formed originally on their surfaces and only then, spreading into the interior enveloping coating material.

2. The lowest values of the friction coefficient and the wear off intensity occurred by the matching of $\mathrm{Cr}_{2} \mathrm{O}_{3}$ coating and $\mathrm{E} 28$ block.

3. In case of $\mathrm{E} 28$ versus $\mathrm{Cr}_{2} \mathrm{O}_{3}$ and $\mathrm{E} 28$ versus $\mathrm{Al}_{2} \mathrm{O}_{3}$ slip pair matchings on the surfaces of test piece and slide block there takes place a stable carbon sublayer formation. A significantly thinner sublayer can be observed in case of WC12Co coated test rings.

4. The wear of plasma sprayed coatings when sliding against a bronze surface is due mainly to the cracking and subsequent tearing off of the joint bronze and plasma coating material sublayer formed earlier between the attrition surfaces.

5. The $\mathrm{Cr}_{2} \mathrm{O}_{3}$ and $\mathrm{Al}_{2} \mathrm{O}_{3}$ plasma coatings are especially for low loaded dry friction pairs in precision machines (such as guides, rollers, ways) as they are characterized by low dry friction coefficient paired with very low wear.

\section{References}

[1] J. Nogueira, A. Ramalho, A. Morao, A. Gaucalves, in: Int. Thermal Spray Conf., Orlando (USA) 1992, Orlando 1992, p. 673.

[2] K. Niemi, P. Vuoristo, T. Mantyla, in: DSV Conference, Essen 1992, Essen 1992, p. 201.

[3] Roll Block T-05 Type Tester, Service Instructions, MCNEMT, Radom 1991. 